\title{
Clinician-Educator Training and Its Impact on Career Success: a Mixed Methods Study
}

\author{
Daniella A. Zipkin, $M D^{7}$ (D), Subha Ramani, MBBS, MPH, $P h D^{2}$, \\ Corrie A. Stankiewicz, MD, MSEd ${ }^{3}$, Margaret C. LO, MD ${ }^{4}$, Alia Chisty, MS, MD”, \\ Irene Alexandraki, MD, MPH', Maria Wamsley, MD', ScottD. Rothenberger, $P h D^{8}$, \\ Kwonho Jeong, $M S^{8}$, and Carla L. Spagnoletti, $M D, M S^{8}$
}

\begin{abstract}
'Department of Medicine, Duke University School of Medicine, Durham, NC, USA; '² Department of Medicine, Harvard Medical School, Brigham and Women's Hospital, Boston, MA, USA; ${ }^{3}$ Department of Medicine, Perelman School of Medicine at the University of Pennsylvania and Corporal Michael J. Crescenz VA Medical Center, Philadelphia, PA, USA; ${ }^{4}$ Department of Medicine, Division of General Internal Medicine, University of Florida College of Medicine, Gainesville, FL, USA; ${ }^{5}$ Division of General Internal Medicine, Penn State Milton S. Hershey Medical Center, Penn State College of Medicine, Hershey, PA, USA; 'Department of Clinical Sciences, Florida State University College of Medicine, Tallahassee, FL, USA; ${ }^{7}$ Division of General Internal Medicine, University of California San Francisco School of Medicine, San Francisco, CA, USA; ${ }^{8}$ Division of General Internal Medicine, University of Pittsburgh School of Medicine, Pittsburgh, PA, USA.
\end{abstract}

BACKGROUND: Clinician-educator (CE) careers in academic medicine are heterogeneous. Expectations for CEs have grown, along with a need to better prepare CEs for these roles.

OBJECTIVE: To assess whether advanced education training is associated with productivity and success.

DESIGN: We used a sequential mixed methods approach, collecting quantitative survey data and qualitative focus groups data. We developed a three-tiered categorization of advanced training to reflect intensity by program type.

PARTICIPANTS: We surveyed CEs in the Society of General Internal Medicine (SGIM) and conducted two focus groups at an SGIM annual meeting.

MAIN MEASURES: Primary outcomes were academic productivity (manuscripts, presentations, etc.) and leadership role attainment. Secondary analysis examined the interactive effect of gender and training intensity on these outcomes.

KEY RESULTS: A total of 198 completed the survey (response rate 53\%). Compared with medium- or lowintensity training, high-intensity training was associated with a greater likelihood of publishing $\geq 3$ first- or seniorauthor manuscripts (adjusted OR 2.6; CI 0.8-8.6; $p=$ 0.002), teaching $\geq 3$ lectures/workshops at the regional/national/international level (adjusted OR 5.7; CI 1.5$21.3 ; p=0.001$ ), and having $\geq 3$ regional/national committee memberships (adjusted OR 3.4; CI 1.0-11.7; $p=$ 0.04). Among participants in the "no training" and "highintensity training" categories, men were more likely to have $\geq 3$ publications (OR 4.87 and 3.17, respectively), while women in the high intensity category had a

Prior Presentations This work was presented as a poster abstract at the Annual Meeting of the Society of General Internal Medicine in Washington DC in 2019.

Electronic supplementary material The online version of this article (https://doi.org/10.1007/s11606-020-06049-w) contains supplementary material, which is available to authorized users.

Received January 21, 2020

Accepted July 10, 2020

Published online August 10, 2020 likelihood similar to men with no training (OR 4.81 vs. OR 4.87). Participants felt the value of advanced training exists not only in content but also in networking opportunities that programs provide.

CONCLUSIONS: While opinions were divided as to whether advanced training is necessary to position oneself for education roles, it is associated with greater academic productivity and reduced gender disparity in the publication domain. Institutions should consider providing opportunities for CEs to pursue advanced education training.

KEY WORDS: clinician-educator; career development; education training.

J Gen Intern Med 35(12):3492-500

DOI: $10.1007 / \mathrm{s} 11606-020-06049-\mathrm{w}$

(C) Society of General Internal Medicine 2020

\section{INTRODUCTION}

Clinician-educator (CE) careers in academic medicine are heterogeneous, ranging from predominantly clinical careers with limited embedded teaching time to careers focused on education leadership and program development. In addition, CE paths for career advancement differ due to variability in promotion criteria among institutions. Historically, a keen interest in teaching was all that was required to become a successful CE and assume education leadership roles; no particular education degree or training was required. Over the last 30 years CEs have encountered growing expectations for service, scholarship, and leadership. Despite the existence of a wide variety of opportunities to acquire skills in medical education, it is unclear whether post-graduate training or degree awarding programs in education skills or scholarship, hereafter referred to as "advanced training," help CEs meet these increasing demands or lead to academic advancement.

Over the last several years, the key roles and competencies for CEs have been better defined, and are now understood to 
include expertise related to curriculum development, education theory, assessment, leadership, and mentorship, among others. Many of these established competencies are not traditionally taught in most residency training programs, leaving CEs responsible for developing these skills in other ways. ${ }^{1,2}$ Several studies have focused on identifying promotion criteria that capture CE's teaching, education scholarship, and clinical service responsibilities. ${ }^{3-5}$ A Canadian study defined a CE as someone who participates in clinical practice, applies education theory to practice, engages in education scholarship, and consults on education issues. ${ }^{1}$ Yet a recent national survey of division chiefs in general internal medicine in the USA found that peer-reviewed publications remain the top priority for nearly half of division chiefs during the promotion process for CEs, indicating that promotion expectations for CEs are variable at different institutions. ${ }^{6}$ As the role of the $\mathrm{CE}$ evolves and becomes more demanding, it is reasonable to ask: Does advanced training help meet these demands and assist with academic career advancement?

In the past, training opportunities for CEs to develop skills in curriculum development, teaching, assessment, and scholarship were limited. ${ }^{7}$ Today, several institutions have training programs in medical education, ${ }^{8,9}$ and many national organizations offer brief as well as longitudinal faculty development courses. ${ }^{10-12}$ Some faculty choose to pursue this advanced training through programs offered by professional medical organizations, certificate programs, clinician-educator fellowships, or master's degrees in education.

Despite the increased opportunities for CEs to gain advanced training, little evidence exists in the literature on whether such preparation translates to accelerated academic advancement, increased job satisfaction, or leadership opportunities. As a result, it can be unclear how to best advise physicians-in-training interested in medical education careers. The objective of this study was to investigate the impact of advanced training on the academic productivity, education leadership role attainment, academic promotion, and perceived job satisfaction of General Internal Medicine CEs.

\section{METHOD}

\section{Survey Instrument}

We utilized a sequential mixed methods approach (quantitative followed by qualitative data collection) to address the study objective. To collect quantitative data, we developed a survey instrument with support from experts in survey development at the Duke Social Science Research Institute (see "Acknowledgments") and through iterative review by members of the Society of General Internal Medicine (SGIM) Education Committee, to obtain both face and content validity. The survey was pilot tested by committee members for both clarity and ease of use. The survey consisted of demographic questions, details of training including any additional fellowships, participation in advanced training, and the impact of advanced training on academic achievement and job satisfaction (see Appendix 1 in the ESM). Advanced training was captured by type, ranging from local faculty development opportunities at one's institution to training courses offered by various organizations, clinical fellowships, and master's degree-granting programs. The impact of advanced training was assessed using a combination of closed-ended questions with Likert-type response options and open-ended narrative responses. The survey was distributed via anonymous online link using Qualtrics software to the SGIM membership from October to December 2017.

\section{Focus Groups}

To obtain in-depth qualitative data, we used purposeful sampling to recruit volunteers from within the survey sample to participate in one of two 60-minute, in-person focus groups at the 2018 SGIM Annual Meeting. The focus groups were planned at the outset of the study, intended as complementary to the quantitative data of the survey. "Opting in" to focus group participation redirected participants to a separate Qualtrics survey to provide contact information, thus keeping all survey responses anonymous. Using open-ended questions, we explored participant perceptions of the impact of advanced training on career advancement and professional satisfaction. Development of focus group trigger questions was guided by analysis of survey data. Although the questions were not piloted in advance, extensive team discussions preceded finalizing of questions. Both focus group discussions were audiotaped and transcribed for accurate analysis. S.R. facilitated the focus groups and D.Z. observed the conversations and recorded field notes.

\section{Data Analysis}

Descriptive statistics were used to characterize the sample of survey participants. Means and standard deviations, as well as medians and interquartile ranges, were calculated for continuous variables; counts and percentages were calculated for categorical variables. Univariable and multivariable statistical techniques were used to analyze quantitative data. Because we listed ten potential education training types in the survey, with many being similar in time commitment and curricular objectives, we grouped the trainings into an "intensity of training" metric to categorize similar types of advanced training together. In this metric, clinician-educator fellowships and master's degree programs in medical education were considered to be high intensity; training courses such as the Harvard Macy Institute Program for Educators in Health Professions or Teaching Educators Across the Continuum of Healthcare (TEACH) certificate program offered by SGIM were considered medium intensity; local/informal faculty development seminars were considered low intensity; and the education training option "none" was considered no intensity. These categories reflect the variable commitment required to participate in the training and the increasing depth that each type of 
training offers. Associations between reported academic productivity and intensity of training were evaluated using logistic regression models with intensity of training as the primary categorical predictor of interest, controlling for number of years since residency training. Relationships between training intensity and leadership attainment were similarly assessed using multivariable logistic regression; relationships between training intensity and promotion and job satisfaction were evaluated using multivariable linear regression. Additionally, these associations were evaluated separately for males and females by including gender and an intensity-by-gender interaction term in the regression models. All statistical analyses were performed using STATA version 15.1 (StataCorp, College Station, TX) assuming a significance level of $\alpha=0.05$, and no adjustments were made for multiplicity.

We analyzed the qualitative data using a general inductive approach. Two authors (D.Z. and C.A.S.) independently coded the focus group transcripts and narrative comments on the surveys. ${ }^{13}$ A third author (S.R.) reviewed and helped finalize the codes. During open coding, each data unit referring to a specific topic was assigned a code. Similar codes were grouped under coding categories. Thematic analysis was then performed to identify key themes that related to the impact of advanced training on career advancement and professional satisfaction, using participants' words. Any ambiguities or disagreements in coding and identification of themes were resolved through consensus during team conference calls.

This study was approved with exempt status by the institutional review board of the Duke University Health System (protocol \#00085284).

\section{RESULTS}

\section{Demographics of Respondents}

A total of 198 CE faculty completed the survey. In 2017, the total membership of SGIM was 2736 , with $40 \%$, or 1094 , identifying any educational role in their membership profile. Because approximately $34 \%$ of SGIM membership was recorded opening email links from the GIM Connect server, we estimate the denominator for potential survey respondents to be 372 , and therefore the estimated response rate is $53 \%$. Demographics of the participants are presented in Table 1. Two-thirds of the participants were female, $43 \%$ had an additional graduate degree, $28 \%$ completed a medical education fellowship, and the most common academic rank was assistant professor (41\%). The majority $(87 \%)$ of the participants reported having participated in faculty development in education, most commonly local/informal training opportunities (Table 2). Women were more likely than men to have completed a fellowship and/or master's degree in medical education $(40 \%$ vs. $27 \%, p=0.029)$.
Table 1 Participant Demographics and Professional Characteristics $(N=198)$

\begin{tabular}{|c|c|c|}
\hline Characteristics & & $n(\%)$ \\
\hline Age, $N(\%)$ & $\begin{array}{l}<30 \\
30-35 \\
36-44 \\
45-55 \\
56-65 \\
>65\end{array}$ & $\begin{array}{l}1(1 \%) \\
39 \\
(20 \%) \\
64 \\
(33 \%) \\
49 \\
(26 \%) \\
30 \\
(16 \%) \\
9(5 \%)\end{array}$ \\
\hline Gender, $N(\%)$ & $\begin{array}{l}\text { Female } \\
\text { Male } \\
\text { No response }\end{array}$ & $\begin{array}{l}123 \\
(62 \%) \\
68 \\
(34 \%) \\
7(4 \%)\end{array}$ \\
\hline Medical degree, $N(\%)$ & $\begin{array}{l}\text { MD } \\
\text { MBBS } \\
\text { DO }\end{array}$ & $\begin{array}{l}194 \\
(98 \%) \\
4(2 \%) \\
0(0)\end{array}$ \\
\hline $\begin{array}{l}\text { Additional graduate degree, } N \\
(\%)\end{array}$ & $\begin{array}{l}\text { MPH } \\
\text { MS } \\
\text { MBA } \\
\text { Other }\end{array}$ & $\begin{array}{l}38 \\
(19 \%) \\
32 \\
(16 \%) \\
3(2 \%) \\
12(6 \%)\end{array}$ \\
\hline $\begin{array}{l}\text { Years since residency } \\
\text { completion, } N(\%)\end{array}$ & $\begin{array}{l}1-4 \\
5-8 \\
9-12 \\
13-16 \\
17-20 \\
>20\end{array}$ & $\begin{array}{l}31 \\
(16 \%) \\
35 \\
(18 \%) \\
30 \\
(15 \%) \\
23 \\
(12 \%) \\
15(8 \%) \\
63 \\
(32 \%)\end{array}$ \\
\hline Residency type, $N(\%)$ & $\begin{array}{l}\text { Categorical IM } \\
\text { Primary care IM } \\
\text { Medicine-pediatrics } \\
\text { Other }\end{array}$ & $\begin{array}{l}125 \\
(63 \%) \\
53 \\
(27 \%) \\
8(4 \%) \\
12(6 \%)\end{array}$ \\
\hline Fellowship, $N(\%)$ & $\begin{array}{l}\text { No } \\
\text { Yes }\end{array}$ & $\begin{array}{l}114 \\
(58 \%) \\
84 \\
(42 \%)\end{array}$ \\
\hline Type of fellowship, $N(\%)$ & $\begin{array}{l}\text { Medical education } \\
\text { fellowship } \\
\text { Other types of fellowship }\end{array}$ & $\begin{array}{l}56 \\
(67 \%) \\
27 \\
(33 \%)\end{array}$ \\
\hline Academic rank, $N(\%)$ & $\begin{array}{l}\text { Instructor } \\
\text { Assistant professor } \\
\text { Associate professor } \\
\text { Professor } \\
\text { Other }\end{array}$ & $\begin{array}{l}18(9 \%) \\
80 \\
(41 \%) \\
54 \\
(27 \%) \\
35 \\
(18 \%) \\
10(5 \%)\end{array}$ \\
\hline
\end{tabular}

\section{Impact of Intensity of Training}

Participants reported that advanced training significantly influenced professional productivity. For the purposes of this analysis, we used the following cutoffs, which represent the median splits of responses: $\geq 3$ manuscripts, $\geq 3$ workshops or committee memberships, and $\geq 6$ mentees. Compared with medium- or low-intensity education training, high-intensity education training was associated with a greater likelihood of publishing $\geq 3$ first- or senior-author peer-reviewed 
Table 2 Participation in Faculty Development in Medical Education by Type $(N=191)$

\begin{tabular}{ll}
\hline \hline Type & $\begin{array}{l}\boldsymbol{n} \text { (\%) respondents who } \\
\text { indicated participation }\end{array}$ \\
\hline $\begin{array}{l}\text { Local FD opportunities } \\
\text { Stanford-based seminars }\end{array}$ & $111(58 \%)$ \\
$\begin{array}{l}\text { Individual courses (not part of } \\
\text { degree program) }\end{array}$ & $43(22 \%)$ \\
$\begin{array}{l}\text { Master's degree in medical } \\
\text { education }\end{array}$ & $31(16 \%)$ \\
Stanford faculty development & $24(13 \%)$ \\
program & $17(9 \%)$ \\
TEACH (SGIM) & $15(8 \%)$ \\
Certificate in medical education & $11(6 \%)$ \\
AAMC MERC & $9(5 \%)$ \\
Harvard Macy program & $19(10 \%)$ \\
Other & $25(13 \%)$ \\
None &
\end{tabular}

manuscripts (adjusted OR 2.6; CI 0.8-8.6; $p=0.002$ ); teaching $\geq 3$ lectures or workshops at the regional, national, or international level (adjusted OR 5.7; CI 1.5-21.3; $p=0.001$ ); and having $\geq 3$ regional or national committee memberships (adjusted OR 3.4; CI 1.0-11.7; $p=0.04$ ) (Table 3). Advanced training was not associated with having a greater number of mentees ( $\geq 6$ ). Though $89 \%$ of participants reported having an education leadership role, this factor was not associated with intensity of education training, with the exception of a dean's office role (adjusted OR 7.9 for high-intensity training; CI $0.9-73.4 ; p=0.029)$ (Table 4).

When academic productivity and leadership attainment outcomes were stratified by gender, the effect of training intensity on authorship varied significantly (see Appendix 2 in the ESM). Among all participants with no training, males were 4.87 times more likely to be productive in the authorship domain than females. Among all participants with high-intensity training, males were 3.17 times more likely to be productive in the authorship domain than females (odds of 15.28 divided by odds of 4.81, from Appendix 2 in the ESM). Males without training are 1.01 times more likely to be productive in the authorship domain than females with high-intensity training (odds of 4.87 divided by odds of 4.81, from Appendix 2 in the ESM). Thus, even though males are more likely to be productive in the authorship domain than females with similar training, high-intensity training for females is associated with a reduction (when compared to males with high-intensity training) or elimination (when compared to males with no training) of this gender disparity.

Over $70 \%$ of respondents reported a positive impact of advanced training on both job satisfaction and career achievement as measured by promotion, with higher likelihood of a positive perception in those with higher levels of advanced training $(p<0.001)$ (see Appendix 3 in the ESM).

\section{Themes from Focus Group Discussions}

A total of 22 participants volunteered to participate in focus groups, and 20 were included in two focus groups (10 people each) held at the 2018 SGIM annual meeting. Two participants declined due to scheduling conflicts. We received demographic information from 18 of the attendees: focus group attendees consisted of 8 assistant professors, 9 associate professors, and 1 professor. One was in New England, seven Mid-Atlantic, eight in the South, one in the Midwest, and one in the Northwest. Nine were female. All were from university-based programs, representing 13 unique programs. Analysis of the qualitative data from focus group discussions generated three major thematic categories: (1) passion for teaching, (2) institutional culture, and (3) advanced training and its impact. Table 5 lists themes and representative quotes from participants under each of these themes and a summary is provided below.

Table 3 Association Between Productivity and Education Training Intensity (High vs. Medium vs. Low vs. None)

\begin{tabular}{|c|c|c|c|c|c|c|c|}
\hline Product type & & All & $\begin{array}{l}\text { High } \\
\text { intensity }\end{array}$ & $\begin{array}{l}\text { Medium } \\
\text { intensity }\end{array}$ & $\begin{array}{l}\text { Lower } \\
\text { intensity }\end{array}$ & None & value $^{\dagger}$ \\
\hline \multirow[t]{2}{*}{$\begin{array}{l}1 \text { st or senior author on } \geq 3 \text { peer-reviewed } \\
\text { manuscripts }\end{array}$} & $N(\%)$ & \multirow[t]{2}{*}{$\begin{array}{l}81 / 179 \\
(45 \%)\end{array}$} & \multirow{2}{*}{$\begin{array}{l}37 / 65 \\
(57 \%) \\
2.6[0.8, \\
8.6]\end{array}$} & $23 / 61(38 \%)$ & $12 / 32(38 \%)$ & $9 / 21(43 \%)$ & 0.122 \\
\hline & $\begin{array}{l}\text { Adj. OR } \\
{[95 \% \mathrm{CI}]}\end{array}$ & & & $0.4[0.1,1.2]$ & $1.0[0.3,3.8]$ & (Reference) & 0.002 \\
\hline \multirow[t]{2}{*}{$\begin{array}{l}\text { Teaching at regional, national, or } \\
\text { international level } \geq 3 \text { times }\end{array}$} & $N(\%)$ & \multirow[t]{2}{*}{$\begin{array}{l}122 / 185 \\
(66 \%)\end{array}$} & $\begin{array}{l}53 / 67 \\
(79 \%)\end{array}$ & $38 / 61(62 \%)$ & $20 / 37(54 \%)$ & \multirow{2}{*}{$\begin{array}{l}11 / 20 \\
(55 \%) \\
\text { (Reference) }\end{array}$} & 0.030 \\
\hline & $\begin{array}{l}\text { Adj. OR } \\
{[95 \% \mathrm{CI}]}\end{array}$ & & $\begin{array}{l}5.7[1.5 \\
21.3]\end{array}$ & $0.8[0.2,2.9]$ & $1.3[0.3,5.0]$ & & 0.001 \\
\hline \multirow[t]{2}{*}{ Published curricula $\geq 1$} & $N(\%)$ & \multirow[t]{2}{*}{$\begin{array}{l}69 / 179 \\
(39 \%)\end{array}$} & $\begin{array}{l}33 / 66 \\
(50 \%)\end{array}$ & $22 / 59(37 \%)$ & $10 / 35(29 \%)$ & $4 / 19(21 \%)$ & 0.055 \\
\hline & $\begin{array}{l}\text { Adj. OR } \\
{[95 \% \mathrm{CI}]}\end{array}$ & & $\begin{array}{l}4.8[1.3 \\
17.5]\end{array}$ & $1.7[0.5,6.2]$ & $1.9[0.5,7.5]$ & (Reference) & 0.017 \\
\hline \multirow[t]{2}{*}{$\begin{array}{l}\text { Regional/national committee } \\
\text { membership } \geq 3\end{array}$} & $N(\%)$ & \multirow[t]{2}{*}{$\begin{array}{l}74 / 185 \\
(40 \%)\end{array}$} & $\begin{array}{l}33 / 67 \\
(49 \%)\end{array}$ & $23 / 62(37 \%)$ & $13 / 37(35 \%)$ & $5 / 19(26 \%)$ & 0.216 \\
\hline & $\begin{array}{l}\text { Adj. OR } \\
{[95 \% \mathrm{CI}]}\end{array}$ & & $\begin{array}{l}3.4[1.0 \\
11.7]\end{array}$ & $1.1[0.3,3.8]$ & $1.9[0.5,7.4]$ & (Reference) & 0.040 \\
\hline \multirow[t]{2}{*}{$\geq 6$ mentees } & $N(\%)$ & \multirow[t]{2}{*}{$\begin{array}{l}102 / 185 \\
(55 \%)\end{array}$} & $\begin{array}{l}36 / 67 \\
(54 \%)\end{array}$ & $33 / 62(53 \%)$ & $22 / 36(61 \%)$ & \multirow{2}{*}{$\begin{array}{l}11 / 20 \\
(55 \%) \\
\text { (Reference) }\end{array}$} & 0.881 \\
\hline & $\begin{array}{l}\text { Adj. OR } \\
{[95 \% \mathrm{CI}]}\end{array}$ & & $\begin{array}{l}1.0[0.3, \\
3.1]\end{array}$ & $0.6[0.2,2.0]$ & $1.6[0.5,5.1]$ & & 0.305 \\
\hline
\end{tabular}

Odds ratios are adjusted for number of years since residency training

'Pearson's chi-square test or Wald test of the null hypothesis that the three odds ratios are simultaneously equal to one 
Table 4 Association Between Leadership and Education Training Intensity (High vs. Medium vs. Low vs. None)

\begin{tabular}{|c|c|c|c|c|c|c|c|}
\hline$\overline{\text { Role }}$ & & $\begin{array}{l}\text { All }(N= \\
184)\end{array}$ & $\begin{array}{l}\text { High }(n= \\
66)\end{array}$ & $\begin{array}{l}\text { Medium }(n= \\
\text { 62) }\end{array}$ & $\begin{array}{l}\text { Lower }(n= \\
\text { 36) }\end{array}$ & $\begin{array}{l}\text { None }(n= \\
\text { 20) }\end{array}$ & $\begin{array}{l}p \\
\text { value }^{\dagger}\end{array}$ \\
\hline Course director & $\begin{array}{l}N(\%) \\
\text { Adj. OR [95\% } \\
\text { CI] }\end{array}$ & $66(36 \%)$ & $\begin{array}{l}28(42 \%) \\
2.5[0.8, \\
8.1]\end{array}$ & $\begin{array}{l}19(31 \%) \\
1.0[0.3,3.4]\end{array}$ & $\begin{array}{l}14(39 \%) \\
2.4[0.7,8.4]\end{array}$ & $\begin{array}{l}5(25 \%) \\
\text { (Reference) }\end{array}$ & $\begin{array}{l}0.371 \\
0.102\end{array}$ \\
\hline Clerkship director & $\begin{array}{l}N(\%) \\
\text { Adj. OR [95\% } \\
\text { CI] }\end{array}$ & $40(22 \%)$ & $\begin{array}{l}11(17 \%) \\
2.0[0.4, \\
10.2]\end{array}$ & $\begin{array}{l}15(24 \%) \\
2.4[0.5,11.8]\end{array}$ & $\begin{array}{l}12(33 \%) \\
5.5[1.1 \\
28.9]\end{array}$ & $\begin{array}{l}2(10 \%) \\
\text { (Reference) }\end{array}$ & $\begin{array}{l}0.128 \\
0.095\end{array}$ \\
\hline Residency program director & $\begin{array}{l}N(\%) \\
\text { Adj. OR [95\% } \\
\text { CI] }\end{array}$ & $77(42 \%)$ & $\begin{array}{l}27(41 \%) \\
2.0[0.6, \\
6.2]\end{array}$ & $\begin{array}{l}28(45 \%) \\
1.5[0.5,4.8]\end{array}$ & $\begin{array}{l}16(44 \%) \\
2.5[0.7,8.4]\end{array}$ & $\begin{array}{l}6(30 \%) \\
\text { (Reference) }\end{array}$ & $\begin{array}{l}0.669 \\
0.479\end{array}$ \\
\hline Core residency faculty & $\begin{array}{l}N(\%) \\
\text { Adj. OR [95\% } \\
\text { CI }]\end{array}$ & $123(67 \%)$ & $\begin{array}{l}45(68 \%) \\
2.1[0.7, \\
6.3]\end{array}$ & $\begin{array}{l}45(73 \%) \\
1.8[0.6,5.3]\end{array}$ & $\begin{array}{l}22(61 \%) \\
1.5[0.5,4.9]\end{array}$ & $\begin{array}{l}11(55 \%) \\
\text { (Reference) }\end{array}$ & $\begin{array}{l}0.428 \\
0.560\end{array}$ \\
\hline Dean's office & $\begin{array}{l}N(\%) \\
\text { Adj. OR [95\% } \\
\text { CI }]\end{array}$ & $26(14 \%)$ & $\begin{array}{l}15(23 \%) \\
7.9[0.9, \\
73.4]\end{array}$ & $\begin{array}{l}8(13 \%) \\
1.9[0.2,17.9]\end{array}$ & $\begin{array}{l}2(6 \%) \\
1.9[0.1 \\
24.3]\end{array}$ & $\begin{array}{l}1(5 \%) \\
\text { (Reference) }\end{array}$ & $\begin{array}{l}0.054 \\
0.029\end{array}$ \\
\hline $\begin{array}{l}\text { National education leadership } \\
\text { role }\end{array}$ & $\begin{array}{l}N(\%) \\
\text { Adj. OR }[95 \% \\
\text { CI] }\end{array}$ & $3(2 \%)$ & $1(2 \%)$ & $2(3 \%)$ & $0(0 \%)$ & $0(0 \%)$ & 0.590 \\
\hline Residency clinic director ${ }^{ \pm}$ & $\begin{array}{l}N(\%) \\
\text { Adj. OR [95\% } \\
\text { CI }]\end{array}$ & $7(4 \%)$ & $3(5 \%)$ & $2(3 \%)$ & $2(6 \%)$ & $0(0 \%)$ & 0.741 \\
\hline \multirow[t]{2}{*}{ GME leadership role } & $\begin{array}{l}N(\%) \\
\text { Adj. OR [95\% } \\
\text { CI }]\end{array}$ & $3(2 \%)$ & $0(0 \%)$ & $0(0 \%)$ & $2(6 \%)$ & $1(5 \%)$ & 0.072 \\
\hline & $\begin{array}{l}N(\%) \\
\text { Adj. OR [95\% } \\
\text { CI }]\end{array}$ & $10(5 \%)$ & $5(8 \%)$ & $4(6 \%)$ & $1(3 \%)$ & $0(0 \%)$ & 0.502 \\
\hline Yes to any leadership role & $\begin{array}{l}N(\%) \\
\text { Adj. OR [95\% } \\
\text { CI] }\end{array}$ & $163(89 \%)$ & $\begin{array}{l}57(86 \%) \\
2.7[0.7, \\
10.4]\end{array}$ & $\begin{array}{l}57(92 \%) \\
3.1[0.7,13.7]\end{array}$ & $\begin{array}{l}34(94 \%) \\
7.8[1.3, \\
48.8]\end{array}$ & $\begin{array}{l}15(75 \%) \\
\text { (Reference) }\end{array}$ & $\begin{array}{l}0.117 \\
0.158\end{array}$ \\
\hline
\end{tabular}

Odds ratios are adjusted for number of years since residency training

'Pearson's chi-square test or Wald test of the null hypothesis that the three odds ratios are simultaneously equal to one

${ }^{*}$ No logistic model due to small numbers of cases

Thematic category 1-Passion for teaching: Participants described a tug of war between clinical responsibilities and teaching, and the challenges of carving out time for education activities. Yet their passion motivated them to dedicate additional time to teaching activities and education training.

Thematic category 2-Institutional culture: This category elucidated two important points: that criteria for $\mathrm{CE}$ advancement are varied across institutions and that a culture which values educators' ongoing development is vital.

Thematic category 3-Advanced training and its impact: Participants discussed how training can be helpful in ways beyond the program's content, including in obtaining leadership roles, in having the opportunity to establish a relationship with a mentor/advocate, in building a valuable toolkit of resources for teaching and scholarship, and in participating in networking and community building.

\section{DISCUSSION}

Our study adds to the literature by demonstrating the value of advanced training in the professional development of general internal medicine CEs, particularly pertaining to academic productivity and career satisfaction. Currently, there is no single defined pathway to becoming a successful CE. Our data can inform the mentoring and career development of physicians-in-training as well as junior faculty by offering guidance on the value of advanced training - not only in the credentials themselves but also in the greater academic productivity and added value to an institution's education mission that such training could facilitate. Our participants stated that it is critical that institutions establish a culture that acknowledges and values the variety of skills and activities brought forth by clinician-educators by committing to their professional growth and actively promoting their academic advancement.

Our findings on the association of advanced training with job satisfaction can be viewed in the context of overall faculty satisfaction in academic medicine. One study reported $21 \%$ of faculty intended to leave academic medicine due to issues related to inclusion, engagement, and perceived insufficiency in institutional support for faculty. ${ }^{14}$ Another survey of academic (non-clinical) faculty who did leave their institutions cited the primary reason being inadequate professional and advancement opportunities. ${ }^{15}$ Our data suggest that among CEs, advanced training is associated with improved career satisfaction, which may improve retention.

While our findings may not be surprising, they support an evolving notion in academic medicine - that being an educator is a discipline distinct from clinical medicine and research. ${ }^{1}$ Being an educator demands a particular skill set that must be developed through specific training. ${ }^{11}$ Over $50 \%$ of education leaders rate a master's degree in education as enhancing the credibility of CEs, with a smaller number viewing faculty 
Table 5 Qualitative Themes and Representative Quotes from Focus Group Discussions

\section{Thematic category \#1: Passion for teaching}

Theme 1a: Tug of war between clinical and teaching

The perception that teaching efforts must be fit around clinical demands

Theme 1b: Carving out time for education activities Educators interested in advancement need to engage in professional development on their own time

\section{Thematic category \#2: Institutional culture}

Theme 2a: Criteria for clinician-educator are varied How institutions value and support advancement of clinician educators
"It's always that tug of war between the clinical activity and doing neat things like this [early AM sessions on teaching skills for younger teachers] (that) advance your skill set"

"So yes, you do it because it because you love it and you have to make up for it later, unless you are given some protected time. So we are having a bit of issues at our institution, too, in terms of fewer and fewer people are getting that protected time."

"You're incredibly busy, overwhelmed junior faculty. But yet you decide to do the MHPE [Masters in Health Professions Education] online on your own time and you do projects. But then you sort of get to be known so that maybe you go from teaching to being a course director, and a course director is salary supported. And you may get that job without the advanced degree if you are really good, but how do you get really good? And how do you get the opportunity?"

"So I think it's necessary, if you want to be a clinician educator, to have some advanced credential to get some protected time. But I think absolutely in academics, if you want to succeed, you have to work on nights and weekends to get ahead, to get people to buy your time. I do not know anybody who succeeds without that" "I completely agree with the statement about medical degree, additional training, as in helping folks to get time, projects, whatever you are looking for, bargaining power. I think it definitely varies from institution to institution"

"...from talking to other colleagues and former colleagues that are now in other institutions, I think it's a little bit more nebulous exactly what that means for a clinician educator than for some other tracks"

"We have a single track promotion system.... And scholarship is very much a requirement of that track, the only track we have. There are pathways. But it's the same big committee which is half basic scientists for promotion. So for us, what's important, what we are doing at our institution, and I'm sure it's true at a few others, is to enable, provide the skills to the clinician educators if they are at such a place of what it is to do educational scholarship that leads to a product that could go on the Med-Ed Portal as well as be published, how to think strategically about being in an interest group that can lead to leadership. Kind of the things we all know and mentor our faculty about. But each school has different needs."

"I was coming from our institution where there's kind of a 'you must have a master's degree' and you get this baseline protection time and there's not much negotiating around that, to going to kind of smaller or less upper echelon [institution] but being given quite weighty, I would say, leadership roles within residency or medical school education"

Theme 2b: Culture that values educators' ongoing development

Ways in which divisions and departments encourage professional development of CEs

"In terms of faculty development, we have a kind of protected half day, actually, and we are lucky in that. So every Friday morning, there's a medical education journal club, a faculty development series, and other things.... it really creates this culture that teaching is important and it's a skill that we can all continue to grow and develop together, and we are constantly learning from one another, our individual teaching styles, the things that we do well, differently, the different innovations going on, both within our department and other departments"

"One important factor I think is also how much support the division will provide, not for protected time for work, but as to how much support they will provide.... Will the division pay for your travel to SGIM, to take the TEACH course? That's an investment ahead of time. Not all divisions do that."

"[Either] dedicating that time that was not reimbursed so that they know who you are, or maybe coming from another institution where you have a reputation and you are in the right place at the right time. So that when that role turns over, you are jumping up and saying, pick me, pick me. So I think that's, it's a little bit of luck...."

"Whether the institution wants to commit the funding for people have at the time, I do not think it matters how many degrees you have"

"At least within our institution... being recently hired without an advanced degree in medical education, I can guarantee you I would not have had a significant amount of protected time to do the work"

"I think it gave the institution kind of a group of people who cared about education, because you had checked that box and actually taken the additional time and effort that it took to take on those additional courses. So it kind of put you in that box of people that cared about it."

"I had a pretty significant teaching role, even though I did not have a lot of background in teaching. I think that's the way it used to be. Whereas now, if you are starting out and you want to have a significant role, I say big E, Clinician Educator, I think you need to have some advanced training"

"You do not just get time because of the degree. You have to show that you are doing something with it."

Theme 3b: Importance of a mentor/advocate The importance of mentoring 
Theme 3c: Building an education toolkit Training helps CEs build an education toolkit and apply strategies that fit the setting

Theme 3d: Networking and community most valuable
"You can take as many courses, whatever, do as much as you-you do not actually have a mentor that actually guides you to see how you can use all those tools effectively."

"And also an advocate to give you protected time to do those things"

"I think it's just adding to your toolkit, so you have more things that you can go and grab and say, I'm going to use this here, use that there."

"I would say for me it would be more inward. It would be more just competency and versatility. Like engaging in those mentorship and teaching programs earlier in my career was about competency and versatility with the learner in front of me."

"It gives you a little bit of a structure. That's what the training gave me. I do not write curriculum, but I can write like a little piece, and at least I know how to write, objective... it at least gave me structure that later on actually I've been using it.'

"I think the med ed certificate program that I did was a lot more, I gained a lot more from the discussions with my colleagues than the content of the courses. I think the networking amongst other educators and finding kind of birds of a feather was really important, because you found other allies in the institution to move forward your educational goals and projects and ideas."

"The content became less important than networking and problem-solving became more important to me. And that became even more true as I've come further in my career."

"Once I built those bridges, it's really great to learn what other institutions are doing, because I have not had that personal experience, and actually just gain by those collaborations different teaching methods and sort of cultures." development programs as sufficient. ${ }^{1}$ The training criteria for medical education are much less defined than for clinical practice or research, perhaps because education time is typically not remunerated and does not directly contribute to the financial viability of the institution. ${ }^{16}$

While we did see an association between advanced training and greater scholarly productivity, we did not see a similar association between additional training and attainment of most education leadership roles. The overall prevalence of having a leadership role in our sample was high, at $89 \%$, and this may have limited our ability to distinguish differences in leadership attainment. It is also possible that scholarly productivity itself is not a predictor of leadership attainment, where other skills may be more valued. Another potential explanation is that the advanced trainings we describe may not include leadership development as a primary focus.

The impact of gender on our findings merits further discussion. Two-thirds of survey respondents were female. While we cannot know the reason for the predominance of women in our sample, women tend to outnumber men in clinician-educator positions. ${ }^{17}$ Previous studies have shown a diminishing proportion of women faculty rising to higher academic levels such as associate professor or professor and to leadership positions. ${ }^{18}$ The reasons for this disparity are complex, and likely include gender differences embedded in the institutional culture as well as variable institutional commitment to eliminating inequity. ${ }^{19,} 20$ In our study, we found that advanced training may lessen the gender gap between men and women in regard to reported authorship. This intriguing finding merits further exploration in larger data sets that follow academic attainment over time. If confirmed by others, this "leveling of the playing field" conferred by advanced training may positively impact other gender disparities in academic medicine such as promotion or longevity.
With regard to the importance of advanced training in securing teaching roles, focus group participants were divided. Many expressed that advanced education credentials are critical when being considered for such roles, while others voiced that obtaining teaching roles is more dependent on being "in the right place at the right time" and that having advanced training is a lesser priority. This variability in participants' beliefs may be explained in part by differences in institutional culture and generational effects, since advanced training has become more prevalent in the past 10 to 20 years. Institutions have increasingly looked more favorably at advanced training when selecting faculty for education leadership roles. ${ }^{1}$ However, participants alluded to larger academic institutions having more rigorous training expectations for their CEs than smaller institutions. Focus group participants emphasized other factors that are important in obtaining roles, such as internal motivation, after-hours work, and seeking out mentorship. In addition, many participants stated that the benefit of advanced training extended well beyond the content of the courses in the form of networking and mentoring which led to ongoing opportunities for collaboration and learning.

\section{LIMITATIONS AND STRENGTHS}

Several limitations of our study merit discussion. Our study sample is small and limited to a self-selected subset of the membership of one organization, SGIM, which limits generalizability. It is likely that our sample did not have sufficient representation from clinicians with less substantial teaching roles, as they may be underrepresented in the organization or may not have taken the survey. We may also have been more likely to miss hospitalist educators, as they may be less likely to maintain membership in SGIM. However, SGIM is the 
principal organization for general academic internists; thus, our study sample is likely representative of internists who teach and practice in academic settings. Second, our survey has not been externally validated. However, our goal was not to develop a tool for widepread use, but rather data gathering, making validation less critical. The survey did not capture information on participants' environments, including geographic region and type of institution, whether university based or community based, and therefore we cannot comment on regional differences. The survey asked about leadership roles but did not strictly define whether such roles came with funded time or were less formal. We also did not ask respondents to name the advanced training that they participated in, and therefore cannot make direct connections between the content of programs and our outcomes.

The survey asked about mentees but did not define what would constitute a mentoring relationship, whether it be formal or more casual. Furthermore, the degree or type of mentorship received by participants of our study may be an unmeasured confounder or contributor to outcomes. We did not collect data on the chief resident year in our survey, which may significantly impact subsequent clinician-educator careers.

In addition, the quantity and quality of academic achievement may be perceived differently from one participant or institution to another. For example, one high impact publication can be more consequential in CE professional attainment than several smaller ones. Nonetheless, we attempted to address this variability by covering a broad range of types of academic products commonly seen in CE roles.

It is also important to remember that the associations we have found do not imply causation. There may be unmeasured confounders such as differences in internal motivation or aptitude among respondents who choose to pursue advanced training. As this study is exploratory in nature, additional confirmatory studies should be performed to corroborate the associations reported in the manuscript.

The primary strength of our study is its unique approach to investigating whether advanced training for CEs is beneficial to career development, a question that had not been previously studied. A common adage in academic medicine is that one should not simply "do" something, one should also "study it." CE career paths certainly merit such study.

\section{CONCLUSIONS}

In conclusion, advanced training is associated with CE productivity and career satisfaction. Teaching and leading education efforts involve a unique skill set distinct from what is gained in clinical training. Perhaps it comes as no surprise that we have found that preparing educators for their roles through advanced training in education may improve their career success and satisfaction. Now the question is, how much training do they need? We recommend that aspiring CEs who wish to specialize in education and seek productivity and promotion within academic medicine should consider pursuing clinicianeducator fellowship training, a master's degree, or other advanced training in education. In addition, these advanced trainings may have a greater impact on career attainment for women than for men, suggesting a possible role in closing the gender gap in career academic attainment. Finally, CEs report that the value of faculty development opportunities in education goes beyond just the content that is taught- they also create networks of support for educators. Perhaps the real key to success is in the community we keep.

Acknowledgments: The authors wish to acknowledge the support of the Society of General Internal Medicine Education Committee and Council. Dr. Zipkin wishes to thank Alexandra Cooper, PhD, Kyle Endres, $P h D$, and Jennifer Bowles, $P h D J D$, of the Duke Social Science Research Institute, spring 2017, for assistance with survey development.

Corresponding Author: Daniella A. Zipkin, MD; Department of Medicine, Duke University School of Medicine, Durham, NC, USA (e-mail: daniella.zipkin@duke.edu).

Funding Information Funding for statistical analysis was provided by the Division of General Internal Medicine at the University of Pittsburgh.

\section{Compliance with Ethical Standards:}

Conflict of Interest: The authors declare that they do not have a conflict of interest.

Ethical Approval: This study was approved with exempt status by the institutional review board of the Duke University Health System (protocol \#00085284).

\section{REFERENCES}

1. Sherbino J, Frank JR, Snell L. Defining the key roles and competencies of the clinician-educator of the 21 st century: a national mixed-methods study. Acad Med. 2014;89:783-9.

2. Srinivasan M, Li ST, Meyers FJ, et al. Teaching as a Competency: competencies for medical educators. Acad Med. 2011;86:1211-20.

3. Jacobs MB. Faculty status for clinician-educators: guidelines for evaluation and promotion. Acad Med. 1993;68:126-8.

4. Beasley BW, Wright SM, Cofrancesco J, Jr, Babbott SF, Thomas PA, Bass EB. Promotion criteria for clinician-educators in the United States and Canada. A survey of promotion committee chairpersons. JAMA. 1997;278:723-8.

5. Lubitz RM. Guidelines for promotion of clinician-educators. The Society of General Internal Medicine Education Committee. J Gen Intern Med. 1997;12 Suppl 2:S71-8.

6. Yeh HC, Bertram A, Brancati FL, Cofrancesco J, Jr Perceptions of division directors in general internal medicine about the importance of and support for scholarly work done by clinician-educators. Acad Med. 2015;90:203-8.

7. Levinson W, Rubenstein A. Integrating clinician-educators into Academic Medical Centers: challenges and potential solutions. Acad Med. 2000;75:906-12.

8. Chen HC, Wamsley MA, Azzam A, Julian K, Irby DM, O'Sullivan PS. The Health Professions Education Pathway: Preparing Students, Residents, and Fellows to Become Future Educators. Teach Learn Med. 2017;29:216-27

9. Bertram A, Yeh HC, Bass EB, Brancati F, Levine D, Cofrancesco J, Jr How we developed the GIM clinician-educator mentoring and scholarship 
program to assist faculty with promotion and scholarly work. Med Teach. 2015;37:131-5.

10. Coates WC, Love JN, Santen SA, et al. Faculty development in medical education research: a cooperative model. Acad Med. 2010;85:829-36.

11. Knight CL, Windish DM, Haist SA, et al. The SGIM TEACH Program: A Curriculum for Teachers of Clinical Medicine. J Gen Intern Med. 2017;32:948-52.

12. Harvard Macy Institute Program for Educators in Health Professions. https://www.harvardmacy.org/index.php/hmicourses/educators. Accessed 11 July 2019.

13. Thomas DR. A general inductive approach for analyzing qualitative evaluation data. Am J Eval. 2006;27:237-46.

14. Pololi LH, Krupat E, Civian JT, Ash AS, Brennan RT. Why are a quarter of faculty considering leaving academic medicine? A study of their perceptions of institutional culture and intentions to leave at 26 representative U.S. medical schools. Acad Med. 2012;87:859-69.

15. Girod SC, Fassiotto M, Menorca R, Etzkowitz H, Wren SM. Reasons for faculty departures from an academic medical center: a survey and comparison across faculty lines. BMC Med Educ. 2017;17:8.
16. Alexandraki I, Mooradian AD. Academic advancement of clinician educators: why is it so difficult? Int J Clin Pract. 2011;65:1118-25.

17. Mayer AP, Blair JE, Ko MG, et al. Gender Distribution of US Medical School Faculty by Academic Track Type. Acad Med. 2014;89:312-317.

18. Butkus R, Serchen J, Moyer DV, et al. Achieving Gender Equity in Physician Compensation and Career Advancement: A Position Paper of the American College of Physicians. Ann Intern Med. 2018;168:721-3.

19. Pololi LH, Civian JT, Brennan RT, Dottolo AL, Krupat E. Experiencing the culture of academic medicine: gender matters, a national study. J Gen Intern Med. 2013;28:201-7.

20. Rao AD, Nicholas SE, Kachniarz B, et al. Association of a Simulated Institutional Gender Equity Initiative With Gender-Based Disparities in Medical School Faculty Salaries and Promotions. JAMA Netw Open. 2018; 1:e186054

Publisher's Note: Springer Nature remains neutral with regard to jurisdictional claims in published maps and institutional affiliations. 